www.jmscr.igmpublication.org

Index Copernicus Value: 79.54

ISSN (e)-2347-176x ISSN (p) 2455-0450

crossref DOI: https://dx.doi.org/10.18535/jmscr/v7i5.152

\title{
Cerebral Proliferative Angiopathy- A Rare Case Report
}

\author{
Authors \\ Madhumita Chandrasekaran, Elamparidhi Padmanaban, Kaviya Varshini. K.S, \\ Kulasekaran. $\mathbf{N}$ \\ Corresponding Author \\ Dr Madhumita Chandrasekaran
}

\begin{abstract}
Cerebral proliferate angiopathy is a rare congenital vascular malformation due to anomalous cerebral angiogenesis causing abnormal cerebral vascular architecture, which differ from other classical arteriovenous malformations. Here we report a case cerebral proliferative angiopathy in a 42 years old male patient which seizure disorder and left hemiparesis. It is essential now to recognize this entity to avoid aggressive treatment or intervention thus we can achieve better prognosis.
\end{abstract}

\section{Case Report}

A 42year old male patient presented with multiple episodes of seizure for past 15 years which is aggravated for past 3 months. Past medial history of cerebrovascular accident 5 year back with left hemi paresis. Patient is also on treatment for diabetes and hypertension. No detectable skin lesion. There is no significant family history of AVM. Laboratory investigations were unremarkable.

\section{Imaging findings:}

Non-contrast computed tomography of the brain performed to evaluated seizure disorder reveled multiple dilated tortuous vessels in left side of perimesencephalic cistern extending into quadrigeminal cistern these vessels are causing compression and displacement of mid brain. Area of gliosis noted in right parietal region. Multiple foci of serpingenous calcification seen in bilateral cerebral hemispheres in both supratentorial and infratentorial parenchyma. They are predominantly located in right parietal region in a gyriform pattern.

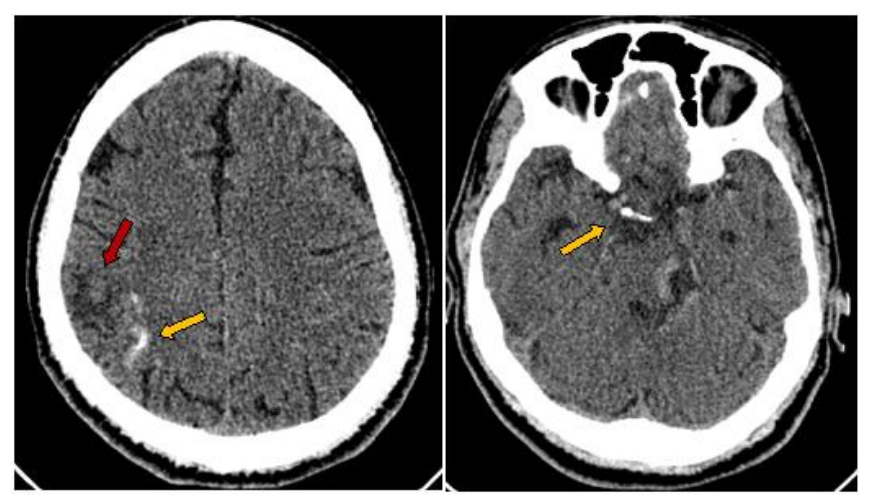

Fig: 1 \& 2 Non enhanced CT axial image showing tortuous hyperdense lesion (yellow arrow) seen in cerebral hemisphere, left $\mathrm{CP}$ angle and ambient cisterns, (left image) foci of gliosis in the right parieto - temporal region (red arrow).

Contrast enhanced computed tomography imaging demonstrated dilated tortuous pial and intra 
parenchymal vessels that are diffusely distended in bilateral supratentorial and infratentorial brain parenchyma. They are located in subcrachroid space, cortical and deep white matter and also in basal cisterns. No focal nidus or feeding arteries seen. Intervening brain parenchyma appears normal except for the foci of gliosis in the right parieto- temporal region suggestive of sequalae of previous ischemic event. No evidence of intra axial or extra axial hemorrhage.

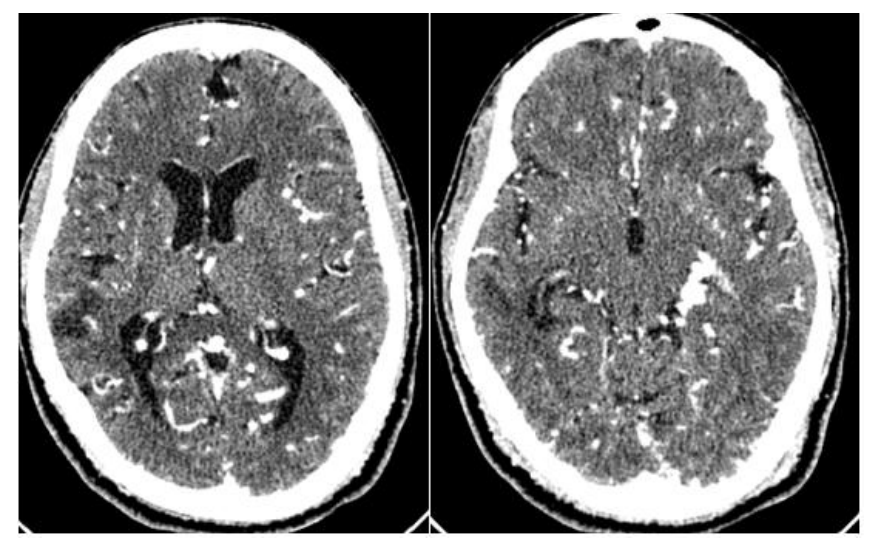

Fig: 2 \& 3 Post contrast enhanced CT axial images shows dilated tortuous pial and intraparenchymal vessels diffusely distended in bilateral supratentorial and infratentorial with intervening normal brain parenchyma except for the area of gliosis.

\section{MRI Findings}

Multiple tortuous flow voids seen in subarachnoid space in bilateral cerebral hemispheres, left CP angle and ambient cisterns. Mass effect noted over the left lateral aspect of brain stem by these tortuous flow voids. T2/FLAIR high intensities seen in the right parieto-temporal lobe which showed no restricted diffusion/Blooming in gradient images. No focal nidus/ feeding arteries/ draining veins. No obvious communication with the dural venous sinuses. No evidence of intracranial/subarachnoid hemorrhage.

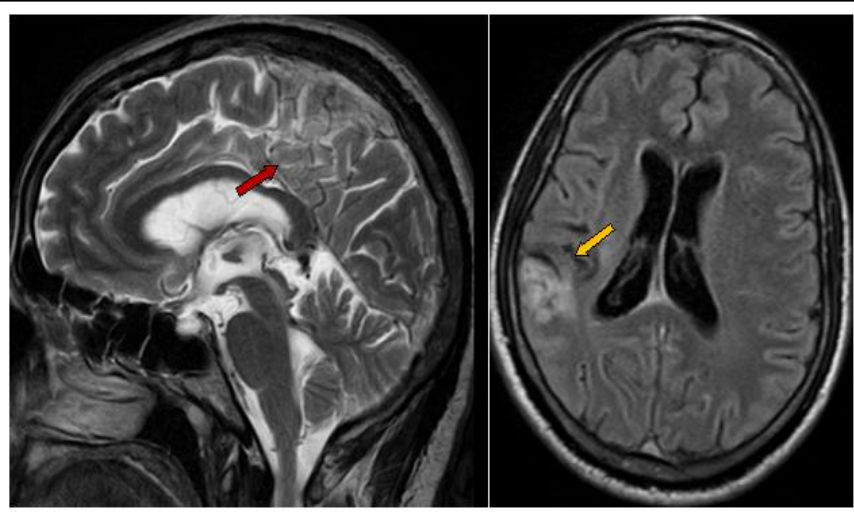

Fig: 4 \& 5 Plain sagittal T2W MR (left) image shows multiple tortuous flow voids seen in subarachnoid space in cerebral hemispheres (red arrow). Axial plain T1W MR (right) image showing hyperintensity in the parieto-temporal region - old infarct changes (yellow arrow).

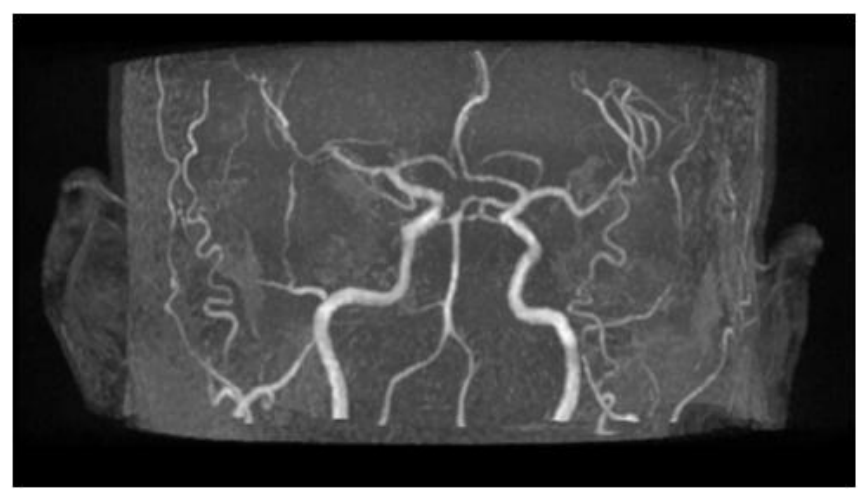

Fig: 6 MR angiography showing multiple dilated vessels with no focal nidus or draining vessels

\begin{tabular}{|l|c|c|}
\hline & Classical AVM & CPA \\
\hline Age & $20-40$ years & $<30$ years \\
\hline Sex & Both & $\begin{array}{c}\text { Female } \\
\text { predominance 2:1 }\end{array}$ \\
\hline Number & Solitary & Multiple \\
\hline Location & Parenchymal 85\% & $\begin{array}{c}\text { Supretentorial 78\% } \\
\text { Infratetiontal 22\% }\end{array}$ \\
\hline $\begin{array}{l}\text { Hemorrhagic } \\
\text { risk }\end{array}$ & Very high & Relatively low \\
\hline $\begin{array}{l}\text { Imaging } \\
\text { features }\end{array}$ & $\begin{array}{c}\text { Bag of worm } \\
\text { appearance } \\
\text { Nidus present } \\
\text { Dilated arterial } \\
\text { feeders } \\
\text { No normal cerebral } \\
\text { tissue inbetwwen the } \\
\text { AVM }\end{array}$ & $\begin{array}{c}\text { Diffuse } \\
\text { involvement } \\
\text { Nidus absent } \\
\text { Normal sized } \\
\text { arteries } \\
\text { Normal cerebral } \\
\text { tissue inbetween } \\
\text { the abnormal } \\
\text { vessels }\end{array}$ \\
\hline Treatment & Surgery & Conservative \\
\hline
\end{tabular}




\section{Discussion}

Cerebral proliferative angiopathy is also known as holo hemosphiric gaint cerebral AVM or diffuse AVM. It is now considered as on separate entity with specific imaging features and natural clinical course.CPM is an rare entity with a prevalence of $3.4 \%$ of all AVM's. CPA has an female predominance of 2:1 ratio. It usually occurs in young females in our case it involves on 42 year old male.

It is hypothesized that CPA occurs due to congenital anomalous cerebral vascular angiogenesis which is resulting in abnormal cerebral angioarchitecture but the pathogenesis still remain unclear. CPA patients present with $45 \%$ of seizure, $41 \%$ of headaches, $16 \%$ of neurological deficit (TIA) and $12 \%$ of hemorrhage. In our case the patient presented with both seizure and old cerebrovascular accident.

CPA has an specific imaging features which make it can an separate entity from classical AVM's which include multiple small arterial feeders and numerous small draining veins and extensive transdural supply with absence of large feeding arteries or flow related aneurysms and absence of nidus. Normal cerebral parenchyma will be intermingled with diffuse vascular network.

CPA may be underrecognized in younger age but it has been seen that the lesion can pregress over the spen of several years.CPA involvement is predominantly supra tentortial with $22 \%$ of infratentorial involvement. In our case, it involves both in supratentorial and infratentorial regions with calcifications. The exact region for calcification is not known but it can be due to arterial steal phenomenon or persistent venous congestion causing calcification in chronic hypoperfused brain or these are due to secondary dystrophic changes in walls of congested veins.

Certain genetic disorder are known to be associated with CPA such as hereditary hemorrhagic telangiectasia, wyburn mason syndrome and sturge weber syndrome. None of these syndromic features are seen in our patient.
The treatment options in CPA is totally different from classical AVM's because of its diffuse involvement. The risk of permanent neurological damage to the patient is more due to normal intermingled cerebral tissue in between the abnormal vessels. So it is important to recognize this entity.

Conservative management provides better prognosis; bevacizumeb on anti angiogenesis, monoclonal antibody that binds to VEGF has been used in some patients with inconclusive results. Targeted partial arterial embolizetion in non eloquent areas can be performed in patients with uncontrolled seizures and headache. Calvarial burrholes that increase carotid blood supply can be done in patients with uncontrolled headaches Gamme knife radiosurgery has been repored to improve the patient symtomatically.

\section{References}

1. Lasjaunias PL, Landrieu P, Rodesch G, Alvarez H, Ozanne A, Holmin S, et al. Cerebral proliferative angiopathy: clinical and angiographic description of an entity different from cerebral AVMs Stroke 2008;39:878-885.

2. Schreiber SJ, Doepp F, Bender A, Schmierer K, Valdueza J M. Difuse cerebral angiomatosis. Neurology 2003;60:1218-1219.

3. H. L. Doria-Netto, A. M. de Souza-Filho, R. H. Doria-Netto et al., "Cerebral proliferative angiopathy," Arq Neuropsiquiatr, vol.68, no. 2, pp. 300-302, 2010.

4. Solmaz I et al. Diffuse Cerebral Arteriovenous Malformation. Turkish Neurosurgery 2010; 20(4):536 539. PMID: 20963707.

5. H. Maekawa, M. Tanaka, and H. Hadeishi, "Fatal hemorrhage in cerebral proliferative angiopathy," Interventional Neuroradiology vol. 18, no. 3, pp. 309313, 2012.

6. Spetzler RF, Martin NA. A proposed grading system for arteriovenous malformations. J Neurosurgery 1986;65:476-483. 
7. M. P. Marks and G. K. Steinberg, "Cerebral proliferative angiopathy," Journal of Neuro Interventional Surgery, vol. 4, no. 5, article e25, 2012.

8. M. Eesa, P. Sharma, and M. Goyal, "Cerebral proliferative angiopathy," Canadian Journal of Neurological Sciences, vol. 36, no. 2, pp. 242243, 2009. 